the extremities of the aged, where the vessels, because of degenerative changes in their coats, become impervious. Collateral circulation, however, is so readily established in the mesenteric vessels, that emboli, unless very complete, can but rarely exert any influence in the production of intestinal ulcer, except as affording a focus for coagulation of blood and the subsequent development of a thrombus. I am inclined to think that deterioration of blood and degenerative changes occurring in the protoplasm of the capillary wall favour the formation of thrombi, and are therefore potent agents in the production of intestinal ulcer. In some cases it is quite possible the cause may be thrombosis, the result of a local phlebitis. Like gastric ulcer, it so far appears to be more common in females than males. Its exciting cause is wholly unknown.

Perforating ulcer is by no means rare. It may occupy any part of the intestinal tract. Most usually it will be found, however, mid-way between the attached and free border of the gut. As a rule, two or three ulcers are to be detected situated close together or at some little distance from each other. They are generally round, but they may be irregular and even somewhat serpiginous in shape. If the perforation be complete, the serous coat usually gives way by rupturing, whilst all the other structures will be found to have necrosed to an equal extent throughout; the muscular coat, however, retracts, and a partial prolapse, so to speak, of the apparently redundant mucous membrane results. One or all of the coats may gradually disappear, the destructive process progressing from within outwards. Recovery may take place at any stage, the loss of tissue being replaced by an exudation and proliferation of cells, which eventually develop new fibrous tissue with a marked proneness to retract, producing a cicatrix of variable shape and size. The affected part of intestine may by a local peritonitis become glued to another part of the bowel or to some other abdominal or pelvic xiscus, and the perforation becoming complete, a fistulous communication may in the course of time be established. If the posterior part of the ascending or the descending colon becomes thus completely ulcerated fæcal extravasation will take place into the underlying areolar tissue outside the peritoneal cavity, and with due care the case may be brought to a favourable termination. It is but seldom that a vessel of any importance gives way producing serious hæmorrhage.

The symptoms of ulcer of the intestine are usually very insidious, and the first intimation of the presence of such a grave condition may be the sudden collapse of the patient, the result of rupture of the bowel and escape of the contents into the peritoneal cavity. Pain as a rule is more or less constant, and is a most troublesome symptom. There is general but no localised tenderness of the abdomen on pressure. Usually there is constipation; occasionally diarrhœa. The temperature may reach $103^{\circ} \mathrm{F}$; generally it is but slightly above normal. The pulse is markedly increased in frequency, averaging from 100 to 120 . The tongue is usually red and irritable. Sometimes there is retention of urine without apparent cause, which is most probably reflex. There is no pain on voiding urine, unless the bladder has become attached to the gut by inflammatory adhesions.

The treatment is complete rest, with bland, easily digested food. Opiates are very essential; they must, however, be judiciously employed.

Montague-street, Russell-square.

West Norfork and Lynn Hospital.-The annual meeting of the governors of this institution was held on the 16th inst., when it was reported that the total number of patients who had received treatment in 1885 was 2437, against 2378 in 1884 . Dr. Lowe, who had for some years acted as consulting surgeon to the institution, having left the town, it was unanimously resolved that he be elected a vice-president of the hospital. The financial state of the charity is not satisfactory, the expenditure having during the past year somewhat exceeded the ordinary income.

Astley Cooper Prize.-The next triennial prize of $£ 300$ will be awarded to the author of the best essay or treatise on the Origin, Anatomy, Results, and Treatment of Tubercular Diseases of Bones and Joints. Essays are to be sent to Guy's Hospital on or before Jan. 1st, 1889, addressed to the physicians and surgeons of that institution.

\section{ON PHIMOSIS IN INFANCY.} BY GEOFFREY HETT M.D.

$M r$ excuse for submitting the following observations on this subject to the consideration of the profession is that my experience leads me to think that phimosis is a morbid condition which is not infrequently overlooked. Its persistence is the cause of much unnecessary suffering among children, and a neurotic habit is often induced which, in some instances, is never shaken off, but continues to exercise a prejudicial effect upon the usefulness and happiness of a considerable number of men during the whole of their lives. It would be advantageous if the following rule were adopted by all those taking charge of midwifery cases: to examine every male child within a few days of birth, and, if the prepuce cannot be retracted by the exertion of a moderate amount of force, to perform circumcision on or about the eighth day of life. The advocacy of such a rule will appear superfluous to many members of the profession, particularly to those who have had special opportunities of observing the diseases of children. That it is, however, not accepted, or, if theoretically accepted, not acted upon by numerous practitioners of midwifery, is suffciently proved by the frequency with which it is necessary to perform the operation in later life. Complete retraction of the prepuce is necessary in order to prevent the retention under it of the secretion of the numerous sebaceous glands in the mucous membrane of the cervix and glans penis (glandulæ Tysonii). The accumulation of this sebaceous matter, acting as a peripheral irritant through the internal pudic nerves, may, and often does, cause central mischief more or less grave according to the constitution of the child and the amount of local irritation. If the preputial opening be so small as to interfere with the easy passage of urine, the condition will be aggravated by some of this fluid being forced under the prepuce and increasing the congestion of the mucous membrane. The injury resulting from this cause may be productive of nothing more than slight peevishness of temper; but, on the other hand, may give rise to convulsive attacks terminating fatally, and, of course, to any effect intermediate between these extremes. I feel sure that many an unfortunate little boy is credited with bad temper and punished for naughtiness whose irritability is due to neglected phimosis, and consequently entirely beyond his own control. There is also much reason for thinking that the habit of masturbation is frequently led up to by a morbidly excitable condition of the sexual organs due to the same cause. Should no symptoms arise sufficiently severe to call attention to phimosis, and the child grow up to manhood with the defect unremedied, the liability to venereal disease must be largely enhanced by the impossibility of effectual ablution of the penis. The operation of circumcision is, in infancy, almost entirely free from risk if ordinary care be exercised. The only objection to it of which I am aware is the æsthetic one, and this cannot have much force in a clothes-wearing community, especially when the advantages derived from it are fully considered. Circumcision may be performed by seizing the extremity of the prepuce between the finger and thumb of the left hand, drawing it well forwards so that the outline of the glands can be clearly seen through the integument of the penis, and slicing it off diagonally downwards and forwards just in front of the glands with a sharp scalpel. The mucous membrane, which will be found still embracing the glands, should be split along the dorsum quite up to the cervix, turned back, and retained in position by a narrow strip of dry lint wrapped firmly three or four times round the penis. No sutures are necessary. The lint becomes saturated with blood, and, when this is dry, remains in position for from two to four days. On its removal the wound will generally be found completely healed, but, if any portion of it be granulating, it only requires the application of a little carbolised oil four or five times a day. I have never seen a case in which the dry lint failed to prevent any excessive hæmorrhage. The eighth day of life is a suitable time for the operation, as the organism of the child has by then become accommodated to its new environment. Inverness-terrace. 